\title{
Public advisory services for early-stage companies in northern sparsely populated area
}

Martti Saarela*

Oulu Southern Institute,

University of Oulu,

Pajatie 5,

85500 Nivala,

Finland

E-mail: martti.saarela@oulu.fi

*Corresponding author

\section{Osmo Kauppila}

Industrial Engineering and Management,

University of Oulu,

Pentti Kaiteran katu 1,

90014 Oulu,

Finland

E-mail: osmo.kauppila@oulu.fi

\section{Eija-Riitta Niinikoski}

Oulu Southern Institute,

University of Oulu,

Pajatie 5,

85500 Nivala,

Finland

E-mail: eija-riitta.niinikoski@oulu.fi

\section{Matti Muhos}

Oulu Southern Institute,

University of Oulu,

Pajatie 5,

85500 Nivala,

Finland

E-mail: matti.muhos@oulu.fi

Pekka Leviäkangas

Department of Construction Management Curtin University

Kent Street,

Bentley WA 610,

Australia

E-mail: pekka.leviakangas@curtin.edu.au 
Public advisory services for early-stage companies in northern sparsely populated area

Biographical notes: Martti Saarela is a Researcher and PhD candidate at Oulu Southern Institute of University of Oulu. He has a Master of Laws and Master of Science in Economics. His primary research interests are the development of micro-companies, public business services, external entrepreneur support, public procurement, and regional development. In recent years, Saarela has been involved in many projects in the area of regional development.

Osmo Kauppila is a Researcher in Industrial Engineering and Management at the University of Oulu. He is responsible for research and education of a wide range of topics in quality management. He holds a M.Sc. in Industrial Engineering and Management. He has worked in both international and national projects regarding quality management in both public and private sectors. His research interests include quantitative methods in management, integrated management systems and quality in higher education.

Dr. Matti Muhos is a Research Director at the Oulu Southern Institute at the University of Oulu. He holds a Doctorate in Industrial Engineering and Management. He participates in the editorial processes of several international journals as an associate editor, quest editor and advisory board member. His primary research interests are growth and the internationalization of technology intensive SMEs including configurations and management viewpoints, the development of micro-companies and SMEs, technology intensive companies, agility, internationalization processes and technology management.

Eija-Riitta Niinikoski is a Development Manager at the Oulu Southern Institute at the University of Oulu. She has a Master of Arts in Theology. Her primary research interests are regional development, the role of higher education institutions in regional development, internationalisation processes and the development of micro-companies and SMEs in rural areas, and management and leadership of expert organizations. Niinikoski has been the manager responsible for many development projects; she has also been involved in several international projects.

Pekka Leviäkangas is Associate Professor at Curtin University and Research Professor in Industrial Engineering and Management at the University of Oulu. He is specialised in impact analysis, cost-benefit analysis and engineering economics. He has worked in and lead recognised international and national research projects. He has advised Finnish ministries, agencies and companies and has contributed to the works of e.g. United Nations organisations (UNECE, WMO) and the OECD (International Transport Forum). 

populated area

\begin{abstract}
In developed countries, the public sector allocates substantial resources to support entrepreneurship. Current literature provides limited evidence on how public advisory services should be efficiently and effectively organised. This study investigated what the perceived significance and service level of public advisory services is. A single case study focusing on a sparsely populated region in Northern Finland was performed by carrying out orientation interviews and a customer survey. As a result of this study, the levels of successfulness and the importance of the public advisory services were clarified from the customers' perspective. The results imply that the services are particularly important in the very beginning of the development of the business. It is also then when the most tailoring is called for. This research includes a novel sample, reflecting experiences particularly from a northern sparsely populated area. The perceived customer value of the services is a significant new viewpoint.

Keywords: public advisory services, public business services, sparsely populated area, micro-sized enterprises, stage models, entrepreneurship support, growth, northern populated areas, perceived customer value, innovation, regional development
\end{abstract}

\title{
1 Introduction
}

Corporations in developed countries have moved their operations to lower-cost locations. As the remaining companies have been able to employ fewer workers, new businesses have become the focus of entrepreneurship policy (Osmonalieva, 2011). In Finland, the role of small- and medium-sized enterprises (SMEs) as sources of employment has been increasing significantly. Rather than following traditional industry-led support policies, SMEs are appearing as significant beneficiaries of public support systems, and substantial resources are allocated via tax funds to support entrepreneurship. Simultaneously, the current downturn in the economy strives to improve the productivity of public services. Hence, a clearer picture of the effectiveness, efficiency and perceived quality of public enterprise support measures is necessary.

Entrepreneurship drives the economy of most nations; SMEs are the fastest growing sector of many economies and are more flexible, adaptable and agile in their responses than larger organisations (Tagliavini et al., 2001; Yifeng, 2011). SMEs can been seen as a backbone of the flexible economy in every country, because they stimulate domestic demand through job creation, innovation and competition (European Commission, 2011; $\mathrm{ADB}, 2014)$. On the other hand, compared to large enterprises, SMEs typically have fewer financial resources, less technical expertise and more limited management skills (Blili and Raymond, 1993; Yifeng, 2011).

The Finnish national strategy is to enhance SMEs, and with the comprehensive entrepreneurship support policy, the government's aim is to help foster businesses, particularly in their early stages and critical paths of growth (The Prime Minister's Office Finland, 2011). One of the policy tools is to improve the preconditions and climate of business through supporting the innovation and research of SMEs. A successful SME 

populated area

sector can be considered a vital contributing factor to growth, development and better living conditions in sparsely populated areas (SPAs).

In addition to direct public financial support of SMEs, a wide range of external advice sources from the private and third sectors is available to entrepreneurs. Professional and technical experts, consultants, the social networks of entrepreneurs, supply chains and customer links represent advice sources from the private sector. Third-sector organisations, such as sector-based trade and professional associations as well as local business associations, provide support that supplements the list. According to Bennett and Robson (1999), support sources appear to be dominated by high trust specialist sources, such as accountants and lawyers, customers, suppliers and business friends; business associations and public suppliers seem to play an important but lesser role.

Public support for entrepreneurship is granted in Finland under a number of policies, including employment policy, regional policy, trade policy, competition policy, entrepreneurship policy and innovation policy (Tokila, 2011). These policies' objectives are actualised under multiple delivery forms of business support, including financing and business services. As a consequence, the responsibility for granting support is dispersed to many different ministries and agencies. This leads to fairly extensive service provision by the public sector (Ministry of Employment and the Economy, 2012). In the Nordic countries, legislation allows local government to take an active part in community development to promote business (Bjornå and Aarsaether, 2010). Thus, public advisory services (PASs) are provided not only by national organisations but also by regional agencies such as science and technology parks, regional development agencies and public companies, and municipalities.

According to Väänänen (2003), it is encouraging that Finnish SMEs are supported throughout their life cycle and that the public sector organisations have developed their cooperation to better serve the customers' needs. However, the services are still complex and scattered from a customer perspective. Partly due to project-based funding and projecttype activities, the field remains mixed and changes frequently (Ministry of Employment and the Economy, 2012). In particular, small and start-up companies have experienced the business support system as unsuitable to their needs. The challenges especially affect entrepreneurial support at regional levels (Veugelers et al., 2009).

The main focus in this study is on public advisory services, which include advisory and counselling services, coaching, incubation and other non-financial assistance for entrepreneurs. In addition to the aforementioned, public business support includes financial supports, tax benefits, loans and loan guarantees, and investment subsidies to the companies. Public business support can be defined in this study as value-based support without any expectation of direct financial returns. Even though governments apparently endeavour to support smaller enterprises, little is known about how effectively and efficiently PASs are provided, not to mention their ultimate impact on SMEs and their economy. Sparsely populated areas in these respects are another angle not well covered by the literature.

Public policies that support SMEs are normally justified on grounds of market failures (e.g. information failures) and the potential presence of positive externalities (Storey, 2008). Hjalmarsson and Johansson (2003) distinguish two levels of public advisory services: operational and strategic. The operational level fits with the neoclassical theory, where the theoretical arguments state that public advisory services usually arise from the need to tackle imperfect markets. SMEs have more limited opportunities to acquire support from external business experts than do larger companies. Hence, the neoclassical approach 
Public advisory services for early-stage companies in northern sparsely populated area

views public advisory services as a market intervention or remedy, used in order to even out the deficiencies of asymmetric and imperfect market information available to SMEs. The strategic level is in line with neo-Austrian theory. In this theory context, the entrepreneur has a vital role in the advisory service process. The power aspects and understanding of the nature of the service encounter are emphasised. According to Boter and Lundström (2005), it is not firms but individuals that do business. This entrepreneurialoriented perspective highlights issues such as how the society motivates people, provides opportunities to develop new business and creates support structures that generate required skills for entrepreneurs.

The number of employees, the volume sales and the worth of assets indicate, among other indicators, businesses' size and growth. However, management must deal with multiple dimensions in a growing company, and there are several factors driving or balking growth. This study engages growth process challenges by reflecting the interviews and surveys to respondent companies' life cycle phases. Synonymous labels for this perspective are stages of growth or configuration (see e.g. Muhos et al., 2010; Muhos, 2011). Numerous models have attempted to capture managerial challenges and priorities in the early stages of companies (see e.g. Churchill and Lewis, 1983; Greiner, 1972). These models also relate to what growth brings to a company and how to manage a growing company (see Davidsson and Wiklund, 2006; Wiklund, 1998). Growth configuration literature reveals diverse managerial problem configurations specific to the different growth stages.

A simplified framework and a synthesis of recent stage models (see Muhos et al., 2014) is applied in this study in the exploration of public advisory services provided by PAS organisation. The intention is to use this framework as a reference framework to classify the PASs provided for companies. According to Lindhult and Höglund (2011), it has recently been shown that it is possible to strengthen the early-stage entrepreneurial process through counselling and structured knowledge. The key characteristics of the 
framework (see e.g. Kazanjian and Drazin (1990), Hanks et al. (1993)) are presented in Figure 1 below.

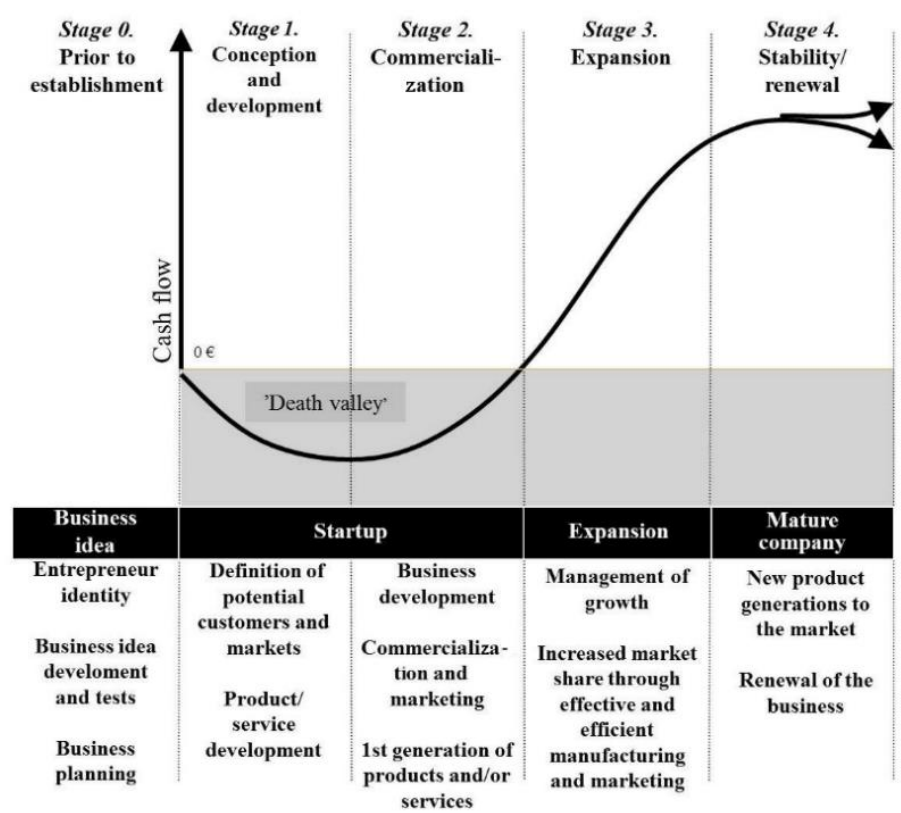

Figure 1. The simplified stage framework of company growth (modified from Muhos (2011).

In the European Union, sparsely populated areas are defined as regions with a population density below 12.5 inhabitants per $\mathrm{km}^{2}$ (Eurostat, 2012). In the Northern European hemisphere, the northern parts of Finland, Sweden and Norway and the majority of Iceland can be defined as sparsely populated areas. These areas are strongly affected by globalisation, energy supply, climate change and demographic change. Peripherality, cold climate, low population densities and dispersed settlement patterns are characteristics of a northern sparsely populated area (NSPA) (Gløersen et al., 2006).

The business environment in NSPAs is different than in urban areas; this modifies the entrepreneurial process and alters the entrepreneurial outcome too. Firms, especially SMEs, may have difficulties in reaching scientific knowledge sources, skilled employees, suppliers, customers and sufficient access to financing. A lack of potential entrepreneurs may also characterise these areas. Remoteness brings about transportation challenges as well as increases in manufacturing costs and longer workforce commutes. On the other hand, the remote location of business can offer low-priced business premises and real estate. PAS actors in NSPAs also face these context-specific challenges as they provide services for their customers. These operating environment challenges emphasise the need for appropriate assistance with respect to market development, exporting, and marketing for small firms (Smallbone et al., 2003).

Boter and Lundström (2005) found that SMEs utilise public support systems in small populated regions more often than in larger regions. One reason for this difference is that while support systems available in larger regions cover a wide spectrum of private and 
Public advisory services for early-stage companies in northern sparsely populated area

public support services, in smaller communities, SMEs may have to depend on fewer public support providers. Results from a survey of small businesses in Britain (Bennett et al., 2000) emphasise the influence of distance, accessibility and, hence, transaction costs (or time) as a dominant force in order to explain the small business choice of business advisors; about $60 \%$ of advisors are from within $10 \mathrm{~km}$ of the customer, and about $80 \%$ from within $25 \mathrm{~km}$.

According to Smallbone et al. (2003), the smaller average size of rural firms compared with urban firms, and thus a greater need of external support, combined with the effect of lower business densities and a greater average distance from private sector business services, indicates a challenge of accessing business support in rural areas. These shortcomings in the external advisory service market make the provision of public sector services, in order to address market failure, all the more important (Smallbone et al., 2003). Bennett and Smith (2002) suggest that small business support policies should be focused mainly towards SMEs which have difficulty in accessing major supply sources due to remote locations; support should be focused on rural and more peripheral areas.

\section{Aim and methodology}

The purpose of this study is first to investigate how customers evaluate and appreciate the importance and current state of provided public advisory services in an NSPA. The "current state' refers to levels of successfulness of the service offering. The 'importance' refers to the perceived significance and impact of the service offering. Then, following the successfulness and significance assessment, these criteria are evaluated against the growth configuration model, that is, in which stages of the life cycle of the respondent companies the services are perceived as most significant and successful. The research problem can be condensed into the following research questions:

1. What is the perceived importance and current state of the public advisory services from the customer perspective in an NSPA?

2. What is the stage-specific perceived importance and current state of services?

This study provides new viewpoints that are relatively less discussed in the literature. The first new viewpoint comes with the geographical scope. Northern sparsely populated areas are seldom tackled with regard to public business services. Secondly, few empirical studies are done about how SME entrepreneurs assess the importance, relevance and quality of the services offered to them. This research at least partly fills these gaps. According to Yin (2013), one rationale for a single case design is to use a common case where the objective 

populated area

is to capture the circumstances and conditions of everyday situations. The key methodological components of this study are presented in Figure 2.

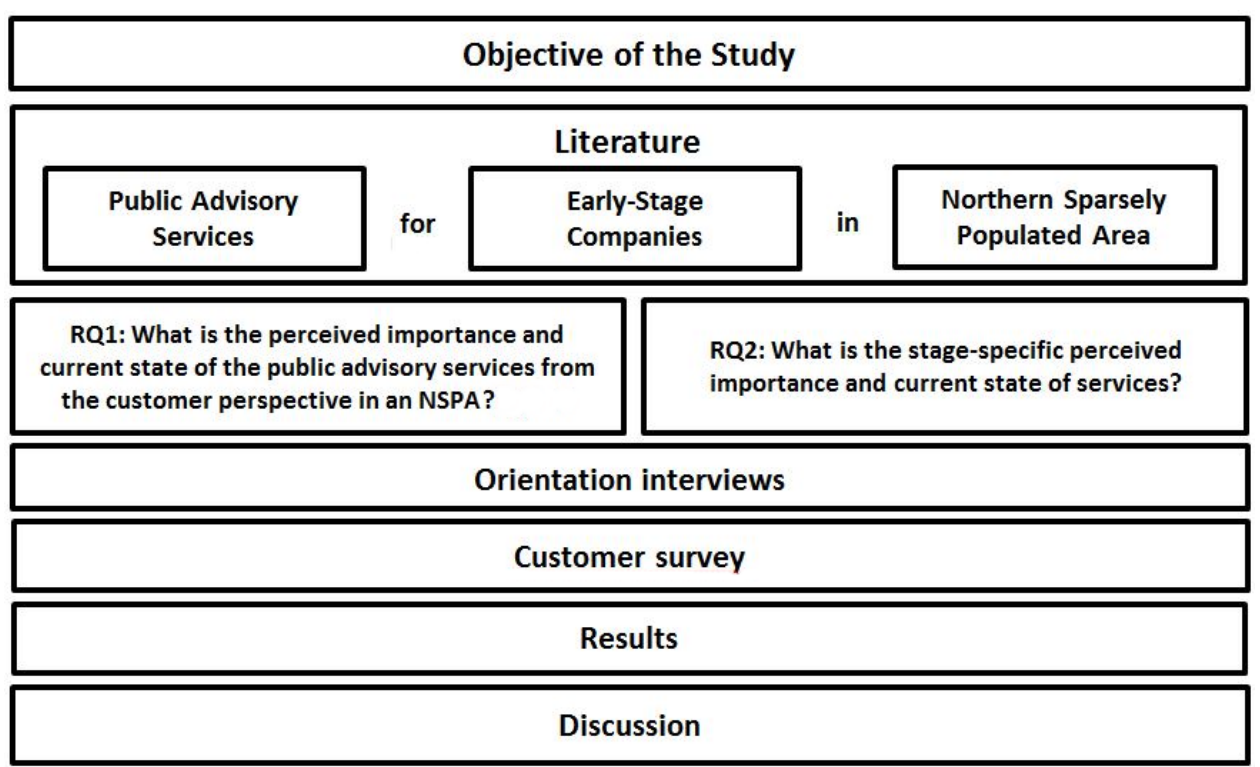

Figure 2. Key methodological components.

The case region of this study, Nivala-Haapajärvi, consists of five municipalities, Haapajärvi, Kärsämäki, Nivala, Pyhäjärvi and Reisjärvi, with a total population of approximately 30,000 inhabitants. The area is located in the southern part of Northern Ostrobothnia in Finland. It covers an area of nearly $4000 \mathrm{~km}^{2}$. The majority $(95 \%)$ of companies in the region are micro-sized companies. Industry, services and primary production comprise about $70 \%$ of the jobs. The growing industrial sectors include the metal and wood products industries. The metal industry, including the construction of metal structures and machinery, equipment manufacturing and mechanical engineering, has strongly increased its workforce in recent years. Nivala-Haapajärvi is the leading 

populated area

region in milk and meat production in Finland. Besides agriculture, forestry has a significant impact on employment in the area as well.

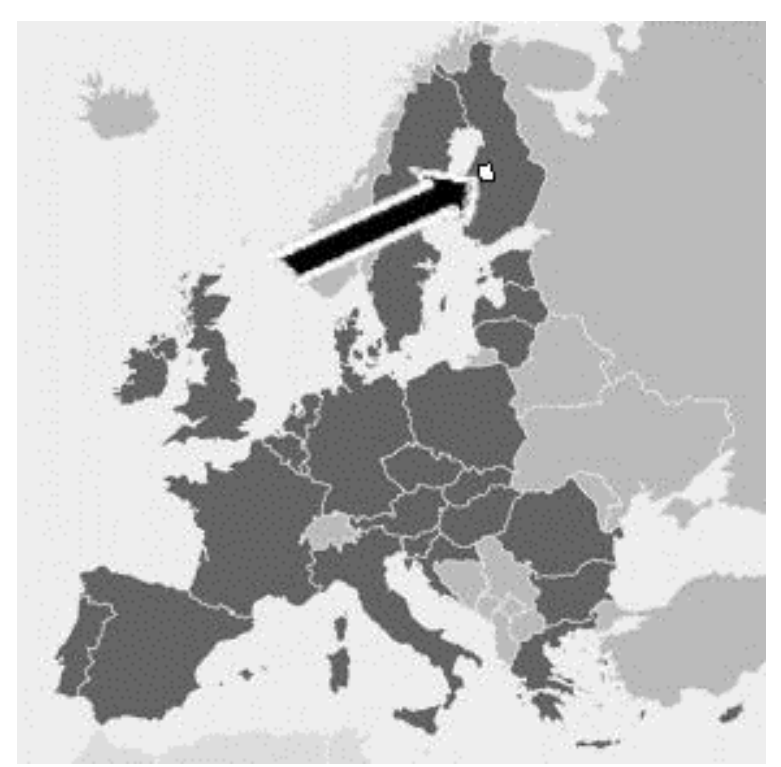

Figure 3. Nivala-Haapajärvi region.

This paper is concerned with the perceived significance and service level of public advisory services within the selected case region, representing a typical area in the NSPA context. According to Gerring (2007), a typical case approach or representative case selection provides insight into broader phenomena. NSPAs face substantially similar challenges, and the case area highlights the circumstances of a typical operation environment of SMEs and PASs.

The remoteness from larger agglomerations, the small size of the local economy and labour market and the unfavourable demographic patterns are highlighted challenges for business in sparsely populated areas (Dubois and Roto, 2012). In addition, NSPAs face special challenges in respect of innovation due to lacks in higher education, research centres, appropriate economic branches of activity, educational attainment of the inhabitants, the capacity to mobilise networks and entrepreneurial culture (Gløersen et al., 2009). The small size of local and regional economies in Europe's sparsely populated areas and the limited local demand means that economic growth potential is strongly related to the capacity of firms, especially smaller ones, to engage in business relations with larger national and international economies (Dubois and Roto, 2012).

In this single case study, both qualitative and quantitative data were used. Prior to the customer survey, orientation interviews were conducted. The purpose of the interviews was to map public advisory services provided for the early-stage SMEs. The orientation round allowed profiling of the services and offerings, so that the more detailed survey design was served. The orientation round consisted of interviews of NIHAK's (Public business agency of the Nivala-Haapajärvi region) top managers (chief executive officer, business development manager and one project manager; altogether, three in-depth, semi-structured 
interviews). The region has arranged its business development services via NIHAK, which is legally registered as a limited company. The background orientation was based on publicly available materials in addition to interviews. All interviews were conducted using a similar process and questions.

The survey data was collected via a web-based questionnaire. Surveys are a common and popular strategy in business and management research (see e.g. Saunders et al., 2012) and are used for exploratory and descriptive research, allowing the collection of standardised data from a sizeable population in a cost-efficient way. The collected data can be analysed further using descriptive and inferential statistics.

In the customer survey, the entrepreneurs were asked to evaluate the importance and the current state of provided advisory services on a service-specific and stage-specific basis, using both closed-ended and open-ended questions. The survey was conducted in the spring of 2012 by sending e-mails and response requests to 857 companies. The questionnaires were sent to all active companies in the region whose e-mail contact information was available in NIHAK's enterprise register. In practice, this register covers actively operating companies of the region. A total of 129 responses were received before the customer survey deadline, the response rate being $15 \%$. A description of the respondent companies is shown in Table 1, below.

Table 1. Description of respondents in survey.

\begin{tabular}{lc}
\hline & Number of staff \\
\hline Solo entrepreneur & 53 \\
2-4 employees & 35 \\
5-9 employees & 24 \\
10-49 employees & 13 \\
$50-249$ employees & 3 \\
250- employees $\quad$ Turnover of company \\
\hline \multicolumn{2}{c}{119} \\
\hline Less than EUR 2 million & 119 \\
Less than EUR 10 million & 6 \\
Less than EUR 50 million & 4 \\
\hline
\end{tabular}

Respondents represent all business sectors and industries, excluding primary production in agriculture and forestry. Of the surveyed companies, 70 had used the provided services, and 59 had not used them. The aggregate features of the sample, in the terms of the number of employees and turnover, compares well with the same aggregate features of the population of companies to which the survey was sent (actively operating companies in the region).

The absolute number of respondents (129) is relatively high and adds to the reliability of the survey. On the other hand, the response rate may raise an opposite question: it may be possible that the respondents participated in the customer survey with greater probability when they had had some experience with PASs. In the interpretation of the results, it must be taken into account that the respondents may not necessarily represent the entire population of 857 SMEs. However, this uncertainty is typical for any statistical sampling.

The customer survey consisted of two sections: a service-specific and an early stagespecific evaluation of the importance and current state of the PASs provided by NIHAK. 
Public advisory services for early-stage companies in northern sparsely populated area

In both sections, the respondents ranked the importance and the current state on a scale of 1 to 5 .

Due to the ordinal nature and skewed distributions of the customer survey responses, nonparametric statistical tests were used to compare the responses. Pairs of survey questions were compared using the Mann-Whitney U test, and for comparisons of multiple questions, the Kruskal-Wallis one-way ANOVA was used. The Mann-Whitney U test is a nonparametric test based on the null hypothesis that the two samples being compared come from the same population. In the research context, this would mean that the respondents ranked the two questions being compared in a similar fashion. The Kruskal-Wallis test is an extension of the Mann-Whitney U test for three or more samples. In the research context, its null hypothesis would imply that all the questions included in the test were answered similarly by the respondents. For cases in which the Kruskal-Wallis test demonstrated statistical significance, the approach proposed by Dunn (1964) was used for pairwise comparisons to identify which pairs of questions differ significantly and to control the family-wise error rate. The response sets to the questions were assumed to be independent from each other. An alpha level of 0.05 was used for all statistical tests.

\section{Results}

\subsection{Results of the interviews of PAS providers}

Based on the interviews, the purpose of the advisory services is to develop several kinds of business activities, excluding primary production in agriculture and forestry. NIHAK has 10 employees working with entrepreneurs. The roles of the personnel are divided into both horizontal (thematic) responsibility (e.g. the incubation services and the services of the growing enterprises) and vertical (local). The latter includes municipal business development consultation responsibility. In every member municipality, there is a business development manager and an office where the entrepreneur receives a start-up package containing information on business development services, following the principle of a 'single window' system. The business development managers are in charge of services in their own municipalities, but they collaborate with each other and function as a network, depending on their areas of expertise.

Table 2. Description of the Nivala-Haapajärvi region.

\begin{tabular}{ll}
\hline \multicolumn{2}{c}{ Nivala-Haapajärvi region } \\
\hline Organisation of services & NIHAK \\
Municipalities & Haapajärvi, Kärsämäki, Nivala, Pyhäjärvi \\
& and Reisjärvi \\
Inhabitants & 30,333 \\
Number of active enterprises & $\sim 1,000$ \\
\hline
\end{tabular}

The main content of the service involves recognising and understanding the process and the life cycle stage of the business activity and then offering the right service. Business development services are confidential and free of charge. The business development managers contact the enterprises in the region annually on a routine basis. Business 

populated area

services and development activities provided by NIHAK for early-stage companies are described in Figure 4.

\begin{tabular}{|c|c|c|c|c|}
\hline $\begin{array}{c}\text { Stage 0: } \\
\text { Prior to } \\
\text { establishment }\end{array}$ & $\begin{array}{c}\text { Stage 1: } \\
\text { Conception and } \\
\text { development }\end{array}$ & $\begin{array}{c}\text { Stage 2: } \\
\text { Commercialisation }\end{array}$ & $\begin{array}{c}\text { Stage 3: } \\
\text { Expansion }\end{array}$ & $\begin{array}{c}\text { Stage 4: } \\
\text { Stability/renewal }\end{array}$ \\
\hline \multicolumn{5}{|c|}{ Customer-based advisory services } \\
\hline \multicolumn{4}{|c|}{ Planning and seeking financing } & $\begin{array}{c}\text { Innovation } \\
\text { services }\end{array}$ \\
\hline $\begin{array}{l}\text { Evaluating the } \\
\text { business idea }\end{array}$ & \multicolumn{3}{|c|}{ Training and building development projects } & $\begin{array}{c}\text { Services upon } \\
\text { ownership and } \\
\text { generational }\end{array}$ \\
\hline $\begin{array}{l}\text { Innovation } \\
\text { services }\end{array}$ & $\begin{array}{c}\text { Studios as } \\
\text { development } \\
\text { environments }\end{array}$ & \multicolumn{3}{|c|}{ Export and import services } \\
\hline $\begin{array}{c}\text { Business } \\
\text { location and } \\
\text { premises } \\
\end{array}$ & \multicolumn{3}{|c|}{ Incubation and growth services } & $\begin{array}{c}\text { Studios as } \\
\text { development } \\
\text { environments } \\
\end{array}$ \\
\hline \multicolumn{2}{|c|}{ Tax advising } & $\begin{array}{l}\text { Marketing } \\
\text { services }\end{array}$ & $\begin{array}{c}\text { Business } \\
\text { location and } \\
\text { premises } \\
\end{array}$ & \\
\hline \multicolumn{2}{|c|}{ Services to organise accounting } & \multicolumn{2}{|c|}{ Networking services } & \\
\hline $\begin{array}{c}\text { Business } \\
\text { planning and } \\
\text { establishing the } \\
\text { business }\end{array}$ & & & $\begin{array}{c}\text { Studios as } \\
\text { development } \\
\text { environments }\end{array}$ & \\
\hline
\end{tabular}

Figure 4. NIHAK's service architecture.

General business advisory services such as consulting, assistant services and intermediary organisations' actions are included in all cells of the above presented figure. Third-party services are offered through the partner networks when the service portfolio does not meet the specific needs of the customer. The support actions of advisory services are not always productised; instead, they are tailored to customers' needs, case by case.

According to the providers, the needs of both established and start-up companies seem to be fairly similar without any larger gaps, despite the companies' varying capabilities to satisfy their own needs. From the perspective of the service providers, targets for future development are location and premises services, internationalisation services and support services for large-scale projects. Even though large-scale projects could be located within the vicinity of small and micro-entrepreneurs, those projects are often difficult for SMEs 

populated area

to participate in. This applies also to internationalisation. The public advisory service is regarded as filling the gap in the capabilities and skills of the customer companies.

According to the interviews with service providers, feedback from customers has been mainly positive, which indicates that NIHAK has a successful service strategy, at least as perceived by the interviewees. In general, those who use the PASs seem to recognise the need for PASs more clearly than non-users. The latter group is also more critical towards PASs. The reason behind negative feedback may be undesired financing decisions or regulatory barriers faced in the receiving of business support. According to service providers' self-assessment, PASs are well-known in their area of operations, especially among the start-ups and early-stage companies and entrepreneurs.

Business service resources and competencies are perceived to be reasonably good, especially if compared to the population and firm sizes of large cities, where conditions lead to better resources in many respects. However, additional staff resources could improve service effectiveness, which could take companies' growth potential further. The maintenance of the competence of personnel is a horse race that requires constant updates. NIHAK tries to ensure the necessary and continuous training and the capacity building of personnel, who consist of experienced professionals, many of whom have a business background. Qualified and experienced experts are able to understand the companies' situations and address appropriate service solutions.

\subsection{Results of the survey}

In the customer survey, the respondents were asked to rate NIHAK's business services presented in Figure 4 for their importance (how relevant, how much impact) and their current state (how good, quality). The results are shown in Figure 5 as percentages of responses. The services are listed in descending order of perceived importance. A more detailed summary of the responses is shown in Appendix 1. 


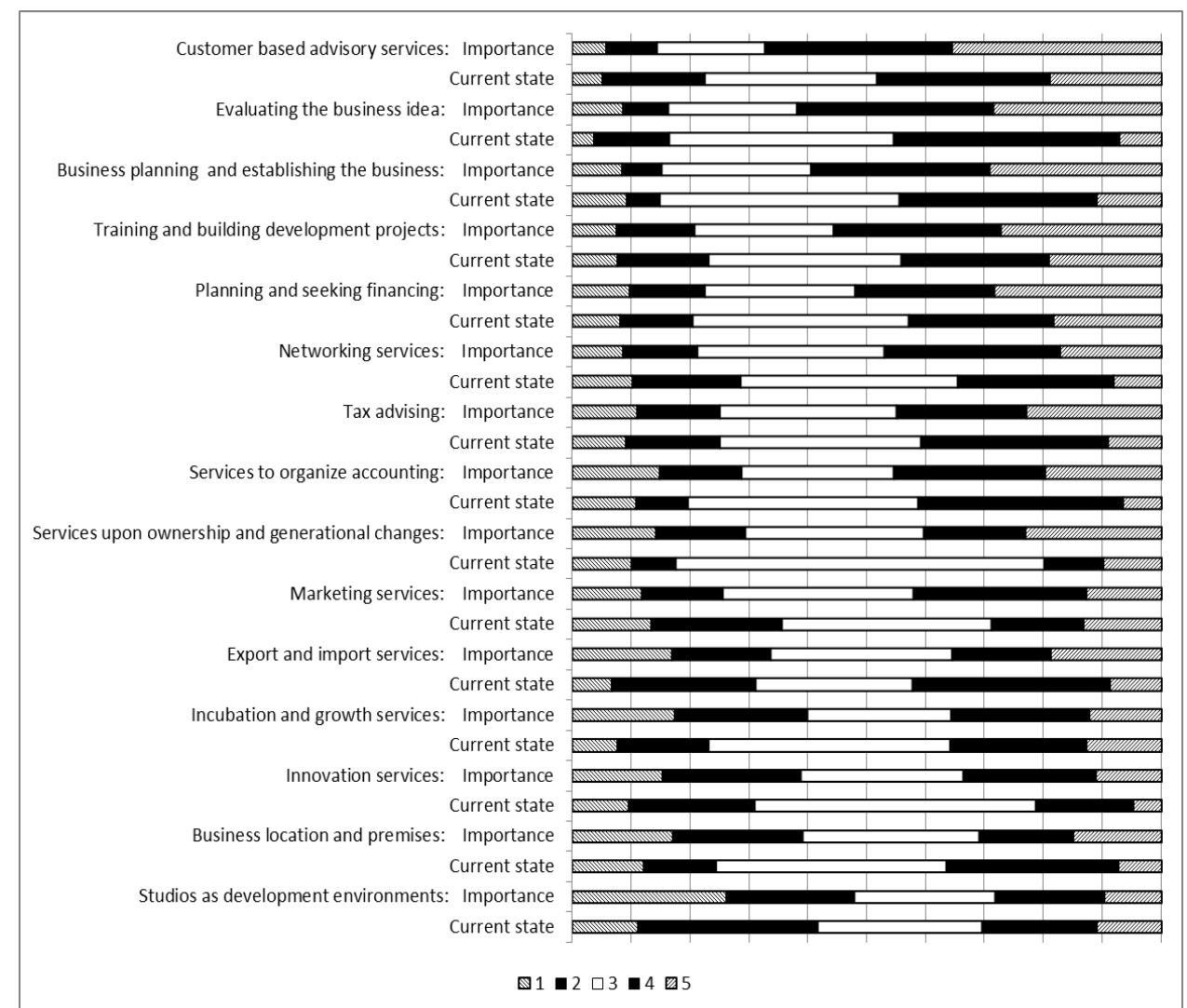

Figure 5. The perceived importance and current state of NIHAK's business services on a scale from 1 to 5 ( 1 = unimportant, $5=$ very important $)$ and evaluation of the current state of PASs, on a scale from 1 to 5 ( 1 = unsuccessful, 5 = very successful).

A comparison of the perceived importance of the services shows a statistically significant difference (Kruskal-Wallis, $\mathrm{p}<0.001$ ). Multiple pairwise comparisons using Dunn's procedure produced a total of 22 significant differences between pairs of the six highest ranked and the seven lowest ranked services in terms of importance. For the perceived current states, there were no statistically significant differences between the services (Kruskal-Wallis, $\mathrm{p}=0.222$ ).

Within each service, statistically significant differences between importance and current state were found in Customer-based advisory services (Mann-Whitney U, $\mathrm{p}=0.013$ ), Evaluating the business idea (Mann-Whitney $\mathrm{U}, \mathrm{p}=0.020$ ) and Business planning and establishing the business (Mann-Whitney $\mathrm{U}, \mathrm{p}=0.040$ ).

According to the customer survey, customer-based advisory services are considered the most important service. The categories of Evaluating the business idea and business planning and Establishing the business seem to be important service packages from the customer perspective as well. According to the responses to the open-ended questions, in terms of current state and developing services, customers expect even more proactivity 
from PAS providers. In addition, customers underlined the need to market the PASs of NIHAK and partner networks even more comprehensively.

The perceived importance and current state of NIHAK's business services in different stages of early-stage companies is presented in Figure 6. The responses of stage-specific evaluation are presented as percentages.

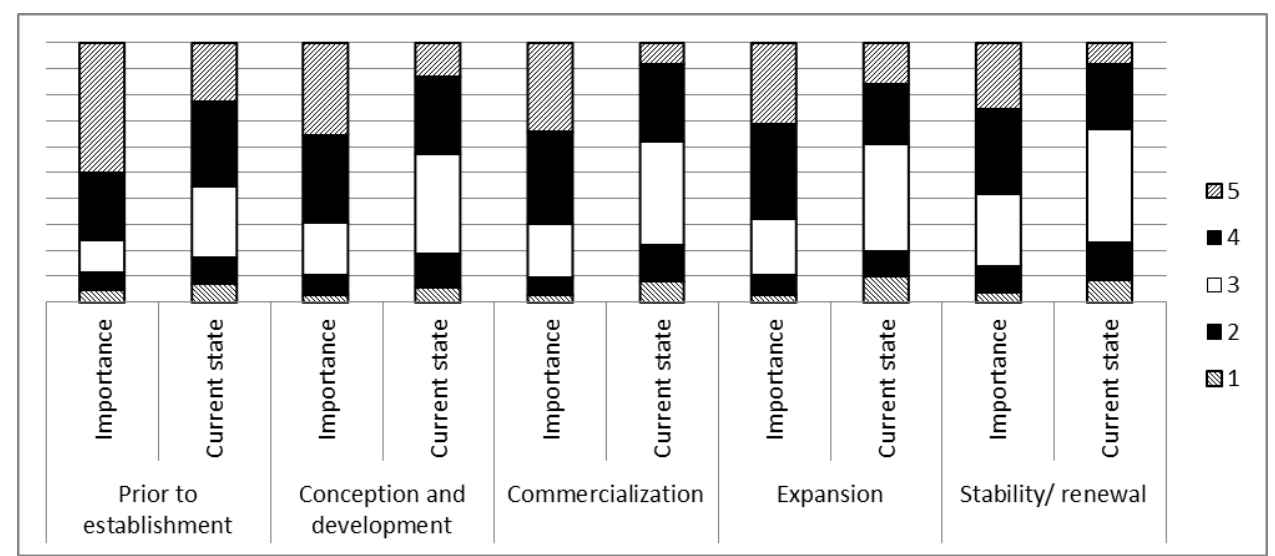

Figure 6. The perceived importance and current state of NIHAK's business services for different stages of early-stage companies on a scale from 1 to $5(1=$ unimportant, $5=$ very important) and the evaluation of the current state of PASs on a scale from 1 to 5 ( 1 = unsuccessful, 5 = very successful).

Table 3 shows how entrepreneurs evaluate the stage-specific importance and current state of PASs provided by NIHAK. Seemingly, customer survey respondents consider customers prior to establishment as the most important target group of the PASs.

Table 3. Stage-specific evaluation of the importance of PASs provided for early-stage companies (stage by stage), on a scale from 1 to $5(1=$ unimportant, $5=$ very important) and stage-specific evaluation of current state of PASs, on a scale from 1 to 5 ( $1=$ unsuccessful, $5=$ very successful).

\begin{tabular}{|c|c|c|c|c|c|c|c|}
\hline \multicolumn{8}{|c|}{ Importance } \\
\hline & $\mathbf{n}$ & 1 & 2 & 3 & 4 & 5 & mean \\
\hline Prior to establishment & 104 & 5 & 7 & 13 & 27 & 52 & 4.1 \\
\hline Conception and development & 104 & 3 & 8 & 21 & 35 & 37 & 3.91 \\
\hline Commercialisation & 103 & 3 & 7 & 21 & 37 & 35 & 3.91 \\
\hline Expansion & 103 & 3 & 8 & 22 & 38 & 32 & 3.85 \\
\hline Stability/renewal & 103 & 4 & 10 & 28 & 33 & 26 & 3.66 \\
\hline Sum & & 18 & 40 & 105 & 170 & 182 & 3.89 \\
\hline \multicolumn{8}{|c|}{ Current state } \\
\hline & $\mathbf{n}$ & 1 & 2 & 3 & 4 & 5 & mean \\
\hline Prior to establishment & 58 & 4 & 6 & 16 & 19 & 13 & 3.53 \\
\hline Conception and development & 54 & 3 & 7 & 21 & 16 & 7 & 3.31 \\
\hline Commercialisation & 50 & 4 & 7 & 20 & 15 & 4 & 3.16 \\
\hline Expansion & 51 & 5 & 5 & 21 & 12 & 8 & 3.25 \\
\hline
\end{tabular}


Public advisory services for early-stage companies in northern sparsely populated area

\begin{tabular}{lccccccc}
\hline Stability/renewal & 48 & 4 & 7 & 21 & 12 & 4 & $\mathbf{3 . 1}$ \\
\hline Sum & & 20 & 32 & 99 & 74 & 36 & $\mathbf{3 . 2 7}$ \\
\hline
\end{tabular}

For the perceived importance between stages, there is a statistically significant difference between some of the stages (Kruskal-Wallis, $p=0.016$ ). A pairwise multiple comparison shows that a significant difference exists between Stage 0 (Prior to establishment) and Stage 4 (Stability/Renewal) (Dunn's, $p=0.006$ ). Services focused on the time before a company's establishment (Stage 0) are rated highest. This is the only group of services with a mean of over 4 . Half of the respondents argue that services prior to establishment are very important; $50 \%$ of the respondents rated them as a 5 on a scale from 1 to 5 . This reinforces the view that PASs are particularly important in the stage before establishing the company. It can also be noted that according to respondents, the importance of the PASs decreases towards the maturity stage of development.

Table 3 shows how customers evaluate the current state of PASs provided by NIHAK for early-stage companies. Services focused prior to establishment are the most successful, according to the respondents. The services focused in the commercialisation and stability stages are rated as the least successful. For the perceived current state, there was no statistically significant difference between the stages (Kruskal-Wallis, $p=0.217$ ).

The difference between perceived importance and current state was found to be statistically significant for each of the stages. To further illustrate the development needs for the case organisation, the differences between the means of importance and the current state were calculated for each stage. As the differences are similarly distributed in each stage, they can indicate which early stages of the company are the most critical for developing the services of the case organisation. The gap between perceived importance and current state is highest in the Commercialisation stage (gap $=0.75$, Mann-Whitney $\mathrm{U}$, $\mathrm{p}<0.001$ ), while four other stages rank quite close: Conception and development (gap = 0.60 , Mann-Whitney $\mathrm{U}, \mathrm{p}=0.001$ ); Expansion ( $\mathrm{gap}=0.60$, Mann-Whitney $\mathrm{U}, \mathrm{p}=0.001$ ); Prior to establishment (gap $=0.56$, Mann-Whitney $U, p=0.001$ ); and the Stability/Renewal stage (gap $=0.56$, Mann-Whitney $U, p=0.003$ ). These results suggest that the case organisation could benefit most from developing the services it provides for companies in the Commercialisation stage. In general, the customer survey results suggest that NIHAK has managed to provide quite successful services for companies in different stages of development. The customers' point of view enhances the providers' understanding of their services.

According to the responses to open-ended questions in terms of the demand for and the importance of PASs, financial issues come up concerning the stage before a company's establishment. Balancing of the finances is described as an important part of business planning. In the conception and development stage, networking, tax issues and cooperation with fund institutions are considered the most important affairs. With regard to the commercialisation stage, respondents emphasised the necessity of services concerning marketing skills, target marketing and competition analysis. Based on the responses to open-ended questions, marketing, networking and internationalisation are seen to be the focal concerns of business services for SMEs in the expansion stage. Expertise services 
and consultancies are emphasised for stability/renewal-stage companies, although PASs are perceived as least important in this target group.

\section{Discussion}

It is well known that SMEs play a central role in national innovation systems and make vital contributions to local development. SMEs' ability to manage innovation can be improved by diffusing an innovation culture, disseminating technological and market information and providing related assistance (OECD, 2001). Via SMEs, PASs can have an indirect influence on the innovation environment and development of the region.

This paper described public advisory services in a northern sparsely populated area and presented the results regarding the customers' satisfaction and perceived importance from service-specific and stage-specific viewpoints. A statistical analysis was carried out with a sample of 129 companies from the region.

According to the respondents to the customer survey, services have been successfully provided in the case region. Customers generally see that the current state of provided services is at quite a good level. The results are consistent with Boter and Lundström's (2005) observation in Sweden, where SMEs using the service support system are fairly positive about the support given to them.

Our findings seem to indicate that entrepreneurs greatly value company-specific services. Customer-based advisory services were seen as the most important service. This is not a surprise, however; each entrepreneur acts very differently, and support mechanisms should be designed in such a way as to meet heterogeneity among SMEs (Boter and Lundström, 2005). Saarela et al. (2014) have also observed that tailoring services is one of the main characteristics of the provision of PASs in NSPAs. Semi-structured services offer the possibility of responding to the entrepreneur's specific needs. Evaluating the business idea and business planning and establishing the business are also important services provided, according to the respondents to the customer survey. It appears that PASs focused on the time prior to establishment of the business are specifically important from the entrepreneurs' perspective. On the other hand, services such as business location and premises and studios as development environments are ranked by entrepreneurs at the bottom of the list. These services are highly focused for a target customer segment, and therefore, a large proportion of companies do not see, for example, the importance of developing studios.

According to the responses to the open-ended questions, customers expect even more proactivity from PAS providers. This is an important development area of the service provision of NIHAK, because a proactive approach to delivery services and the use of outreach activity, including face-to-face meetings and peripatetic advisors, are essential in rural areas (Smallbone et al., 2003). In addition, customers underlined the need to market the advisory services even more comprehensively. This is in line with the survey results of Audet et al. (2007), according to which the main barrier that prevents SMEs from making maximum use of public support services is a lack of knowledge about the service provision.

Based on the customer survey with respect to stage-specific results concerning the importance of PASs provided for early-stage companies, there appears to be a demand for those services in the region; enterprises consider PASs as valuable. Of note is that $50 \%$ of respondents viewed services provided before a company's establishment (Stage 0 ) as very meaningful, evidenced by their maximum rating of 5 . However, the importance of the PASs decreases stage by stage over the life of the business. This result is consistent with 

populated area

Audet and St-Jean (2007), who found that the probability of using public support services decreases as the experience of the owner-manager increases.

Stage-specific results of the open-ended questions provide more details regarding the importance of services in terms of the demand. Respondents emphasise the necessity of services which are dissimilar at different stages, which highlights the need to take into account the companies' varied needs at different stages of the companies' growth.

Based on the customers' responses, the most significant gap between the importance and current state of services is at the commercialisation stage. A closer look at this gap can be taken by analysing answers to the open-ended questions concerning the commercialisation stage. The respondents see the need for guidance in marketing, financing and understanding the commercial competition at this stage. On the other hand, services for expansion-stage companies have the smallest gap between the importance and current state of the services. Nevertheless, respondents to the open-ended questions regarding this expansion stage see the need for internationalisation services and marketing courses as well as for mentoring and networking services.

According to Bennett and Robson (1999), the level of trust seems to explain the use of external advice. Advice services depend a great deal on personal relationships and exchanges. External advice sources have different levels of trust. The level of trust and the balance of personal trust and institutional trust will lead to different extents and intensity in the use of services from different sources. The concept of trust involved in public advisory services is likely to be mainly institutional, based on quality assurance, recommendations and awareness campaigns. Even though PASs are not currently restricted to geographical locations, mostly because of the advances of information and communication technology, personal relationships appear to be an essential part of the successful customer relationship. The personalised approach between business service managers and entrepreneurs is a precondition of trust, which enables a confidential and open atmosphere for discussion about the entrepreneur's situation, which may be a personal and difficult subject. In the advisory system, people are more important than business plans (Lindhult and Höglund, 2011). Due to the essential requirement of a personal level of trust between the PAS provider and the entrepreneur, it is a pertinent challenge for PASs to organise services successfully in SPAs.

This study provides support for the managers of PASs who are considering or currently using a stage framework as the framework for providing more accurate services for earlystage companies. Stage frameworks can offer help to prepare for some of the central activities of the early stages and can help predict the key managerial focus areas and allocate resources in a more focused manner. By analysing the early stages framework, providers of PASs can analyse and enhance existing service portfolios. In addition, the stage framework is useful in reflecting ongoing realities in a company; the assessment of the current stage and the related potential key challenges may be useful in the midst of overwhelming operative tasks.

Finally, the implications for wider SME policies are quite obvious. SMEs and entrepreneurs need PASs in NSPAs, and those who have used them have appreciated them. Entrepreneurs facing the critical decision of whether to establish a company or not are at the very core of the policy. Nations and regions that are successful in targeting this critical stage are likely to be more successful in their entrepreneurial and industrial policies and strategies than those who do not recognise this focal decision-making point. This is not to say that other stages in the life cycle of SMEs are not relevant; they surely are. Most services offered through the life cycle stages are perceived as important, and scaling up a 
business, in particular to national or even international markets, calls for consultation. SMEs will most likely benefit by such support, and that, in turn, in the most positive cases, will lead to true macro-economic value added.

In the light of this research, the case region's PAS policy can be regarded as somewhat successful. Considering the importance of location to a customer's access to business advice (Bennett et al., 2000), a strong local presence is an obvious merit of the embodiment of the policy, and this benefits SMEs in particular. The manoeuvre room available for PAS experts to tailor the services is also a recognisable strength. This signals that in the end, people matter most, not procedures or administrational processes. However, the customerbased approach can also present a challenge, since a particular type of service that is considered high quality by one customer may be considered low quality by another. The fact that customers leave the service apparently satisfied can provide little information about what makes customers satisfied and how the service can improve (Kakouris, 2014).

According to Yin (2013), a case study is generalisable to theoretical propositions but not to populations or universes. From the generalisation perspective, this study, as a common case, can provide new insights into providing PASs in an NSPA context. Although focused on Finland, these issues are of wider international significance, as NSPAs and sparsely populated areas in many countries are increasingly influenced by structural change.

The results of this study represent the viewpoint of a PAS organisation and its customer companies in a northern sparsely populated area. Their viewpoints might differ from those of similar organisations in different business environments, because of context-specific variables. It would be interesting to compare these findings to those of a similar analysis made in PASs located in sparsely populated areas in other European countries, in the USA, or in Asia.

\section{References}

ADB (2014) ADB-OECD Study on Enhancing Financial Accessibility for SMEs: Lessons from Recent Crises, No RPT146403-2, ADB Reports, Asian Development Bank (ADB).

Audet, J., Berger-Douce, S. and St-Jean, E. (2007) 'Perceptual barriers preventing small business owners from using public support services: evidence from Canada', International Journal of Entrepreneurship, Vol. 11. pp. 27-48.

Audet, J. and St-Jean, E. (2007) 'Factors affecting the use of public support services by SME owners: evidence from a periphery region of Canada', Journal of Developmental Entrepreneurship, Vol. 12 No. 2, pp. 165-180.

Bennett, R.J. and Robson, P.J.A. (1999) 'The use of external business advice by SMEs in Britain', Entrepreneurship \& Regional Development, Vol. 11 No. 2, pp. 155-180.

Bennett, R.J., Bratton, W.A. and Robson, P.J.A. (2000) 'Business advice: the influence of distance', Regional Studies, Vol. 34 No. 9, pp. 813-828.

Bennett, R.J. and Smith, C. (2002) 'The influence of location and distance on the supply of business advice', Environment and Planning, Vol. A 34, pp. 251-270.

Bjornå, H and Aarsaether, N. (2010) 'Local government strategies and entrepreneurship', International Journal of Innovation and Regional Development, Vol. 2 No. 1/2, pp. $50-65$. 

populated area

Blili, S. and Raymond, L. (1993) 'Information technology: threats and opportunities for small and medium-sized enterprises', International Journal of Information Management, Vol. 13 No. 6, pp. 439-448.

Boter, H. and Lundström, A. (2005) 'SME perspectives on business support services: the role of company size, industry and location', Journal of Small Business and Enterprise Development, Vol. 12 No. 2, pp. 244-258.

Churchill, N.C. and Lewis, VL. (1983) 'The five stages of small business growth', Harvard Business Review, Vol. 61 No. 3, pp. 30-50.

Davidsson, P. and Wiklund, J. (2006) 'Conceptual and empirical challenges in the study of firm growth' in Davidsson, P., et al. (Eds.), Entrepreneurship and the Growth of Firms, Edward Elgar Publishing, Cheltenham, pp. 39-61.

Dunn, O.J. (1964) 'Multiple comparisons using rank sums', Technometrics, Vol. 6 No. 3, pp. 241-252.

Dubois, A. and Roto, J. (2012) Making the best of Europe's sparsely populated areas: on making geographic specificity a driver for territorial development in Europe, Nordregio Working Paper 2012:15.

European Commission. (2011) Proposal for a directive of the European parliament and of the Council on public procurement. Brussels, 20.12.2011 COM(2011) 896 final 2011/0438 (COD) C7-0006/12 EN.

Eurostat. (2012) 'Regional Typologies Overview - Statistics Explained'

http://ec.europa.eu/eurostat/statisticsexplained/index.php/Regional_typologies_overview. (Accessed 6 February 2013).

Gerring, J. (2007) Case Study Research: Principles and Practices. Cambridge University Press. Avenue of the Americas, New York.

Gløersen, E, Dubois, A, Copus, A and Schürmann, C. (2006) 'Northern peripheral, sparsely populated regions in the European Union and in Norway', Nordregio Report 2006 (2), Stockholm.

Gløersen, E., Dubois, A., Roto, J., Rasmussen, R. O. and Sterling, J. (2009) Development perspectives for the NSPA: Opportunities and Challenges. Nordregio Electronic Working Paper 2009:3.

Greiner, L. (1972) 'Evolution and revolution as organisations grow', Harvard Business Review, Vol. 50 No. 4, pp. 37-46.

Hanks, S.H., Watson, C.J., Jansen, E. and Chandler, G.N. (1993) 'Tightening the life-cycle construct: a taxonomic study of growth stage configurations in high-technology organizations', Entrepreneurship: Theory and Practice, Vol. 18 No. 2, pp. 5-29.

Hjalmarsson, D. and Johansson, A.W. (2003) 'Public advisory services - theory and practice', Entrepreneurship and Regional Development, Vol. 15 No. 1, pp. 83-98.

Kakouris, A.P. (2014) 'Service quality in new public management', Encyclopedia of Quality of Life and Well-Being Research, pp. 5849-5854.

Kazanjian, R.K. and Drazin, R. (1990) 'A stage-contingent model of design and growth for technology based new ventures', Journal of Business Venturing, Vol. 5 No. 3, pp. 137-150.

Lindhult, E. and Höglund, J. (2011) 'Product, process and person orientation in business advisory services', E. Segelod et al. (Eds.), Studies in Industrial Renewal-Coping with Changing Contexts, Mälardalen University, pp. 357-368.

Ministry of Employment and the Economy. (2012) 'Public business services in regions', Publications of the Ministry of Employment and the Economy 45/2012. Helsinki, 

populated area

Ministry of Employment and the Economy. (in Finnish: Julkiset yrityspalvelut alueilla)

Muhos, M. (2011) Early stages of technology intensive companies. Dissertation, Acta Universitatis Ouluensis. C 381. University of Oulu.

Muhos, M., Kess, P., Phusavat, K. and Sanpanich, S. (2010) 'Business growth models: review of past 60 years', International Journal of Management and Enterprise Development, Vol. 8 No. 3, pp. 296-315.

Muhos, M., Kess, P., Distanont, A., Phusavat, K. and Sanpanich, S. (2014) 'Early stages of technology-intensive companies in Thailand and Finland', International Journal of Economics and Business Research (IJEBR) Special Issue on Entrepreneurship in Emerging Markets: Firm Formation, Firm Growth, and Firm Transformation, Vol. 7 No. 2, pp. 177-197.

OECD (2001) 'Enhancing SME Competitiveness'. The OECD Bologna Ministerial Conference. OECD Publishing.

Osmonalieva, Z. (2011) 'Entrepreneurship support', in Segelod, E. et al. (Eds.), Studies in industrial renewal - coping with changing contexts, Mälardalen University, pp. 343-355.

Saarela, M., Niinikoski, E-R. and Muhos, M. (2014) 'Public business services fostering growth - case studies in northern sparsely populated areas', International Journal of Innovation and Regional Development, Vol. 5 Nos. 4/5, pp. 367-383.

Saunders, M., Lewis, P. and Thornhill, A. (2012) Research Methods for Business Students, Essex: Pearson.

Smallbone, D., Baldock, R. and North, D. (2003) 'Policy support for small firms in rural areas: the English experience', Environment and Planning, Part C, Government \& Policy, Vol. 21 No. 6, pp. 825-841.

Storey, D. (2008) "Entrepreneurship and SME policy", World Entrepreneurship Forum.

Tagliavini, M., Ravarini, A. and Antonelli, A. (2001) 'An evaluation model for electronic commerce activities within SMEs', Information Technology and Management, Vol. 2 No. 2, pp. 211-230.

Tokila, A. (2011) 'Econometric studies of public support to entrepreneurship', Jyväskylä Studies in Business and Economics, 1457-1986(104). University of Jyväskylä.

The Prime Minister's Office Finland (2011) Programme of Prime Minister Jyrki Katainen's Government, 22 June 2011.

Veugelers, R., Aiginger, K., Breznitz, D., Edquist, C., Murray, G., Ottaviano, G., Hyytinen, A., Kangasharju, A., Ketokivi, M., Luukkonen, T., Maliranta, M., Maula, M., Okko, P., Rouvinen, P., Sotarauta, M., Tanayama, T., Toivanen, O. and Ylä-Anttila, P. (2009) Evaluation of the Finnish National Innovation System Full Report. Taloustieto Oy, Helsinki.

Väänänen, L. (2003) 'Public provision of business support services in Finland' Discussion Paper No. 850. Helsinki: ETLA, Elinkeinoelämän Tutkimuslaitos, The Research Institute of the Finnish Economy. [online] https://www.econstor.eu/dspace/bitstream/10419/63769/1/362647593.pdf (Accessed 16 September 2013)

Wiklund, J. (1998) Small Firm Growth and Performance: Entrepreneurship and Beyond. Dissertation, Jönköping University, Jönköping International Business School, Jönköping. 

populated area

Yifeng, X. (2011) 'Open innovation of small and medium sized enterprises and R \& D public service platform: a case about the VIC model of Zhangjiang Hi-tech Park'. E-Business and E-Government (ICEE), 2011 International Conference, IEEE, pp. 1-4.

Yin, R.K. (2013) Case Study Research: Design and Methods. Sage Publications, Thousand Oaks, CA. 
Public advisory services for early-stage companies in northern sparsely populated area

Appendix 1. Survey respondents' perceptions of NIHAK's business services.

\begin{tabular}{|c|c|c|c|c|c|c|c|c|c|}
\hline & & $\mathbf{N}$ & 1 & 2 & 3 & 4 & 5 & Mean & St.dev. \\
\hline \multirow{2}{*}{$\begin{array}{l}\text { Customer based advisory } \\
\text { services }\end{array}$} & Importance & 104 & 6 & 9 & 19 & 33 & 37 & 3,83 & 1,18 \\
\hline & \begin{tabular}{|l} 
Current \\
state
\end{tabular} & 58 & 3 & 10 & 17 & 17 & 11 & 3,40 & 1,14 \\
\hline \multirow[b]{2}{*}{ Evaluating the business idea } & Importance & 105 & 9 & 8 & 23 & 35 & 30 & 3,66 & 1,22 \\
\hline & $\begin{array}{l}\text { Current } \\
\text { state }\end{array}$ & 55 & 2 & 7 & 21 & 21 & 4 & 3,33 & 0,92 \\
\hline \multirow{2}{*}{$\begin{array}{l}\text { Business planning and } \\
\text { establishing the business }\end{array}$} & Importance & 106 & 9 & 7 & 27 & 32 & 31 & 3,65 & 1,21 \\
\hline & $\begin{array}{l}\text { Current } \\
\text { state }\end{array}$ & 54 & 5 & 3 & 22 & 18 & 6 & 3,31 & 1,06 \\
\hline \multirow{2}{*}{$\begin{array}{l}\text { Training and building } \\
\text { development projects }\end{array}$} & Importance & 106 & 8 & 14 & 25 & 30 & 29 & 3,55 & 1,24 \\
\hline & $\begin{array}{l}\text { Current } \\
\text { state }\end{array}$ & 52 & 4 & 8 & 17 & 13 & 10 & 3,33 & 1,18 \\
\hline \multirow[b]{2}{*}{ Planning and seeking financing } & Importance & 102 & 10 & 13 & 26 & 24 & 29 & 3,48 & 1,30 \\
\hline & $\begin{array}{l}\text { Current } \\
\text { state }\end{array}$ & 49 & 4 & 6 & 18 & 12 & 9 & 3,33 & 1,16 \\
\hline \multirow[b]{2}{*}{ Netw orking services } & Importance & 104 & 9 & 13 & 33 & 31 & 18 & 3,35 & 1,16 \\
\hline & \begin{tabular}{|l}
$\begin{array}{l}\text { Current } \\
\text { state }\end{array}$ \\
\end{tabular} & 49 & 5 & 9 & 18 & 13 & 4 & 3,04 & 1,10 \\
\hline \multirow[b]{2}{*}{ Tax advising } & Importance & 100 & 11 & 14 & 30 & 22 & 23 & 3,32 & 1,28 \\
\hline & $\begin{array}{l}\text { Current } \\
\text { state }\end{array}$ & 44 & 4 & 7 & 15 & 14 & 4 & 3,16 & 1,10 \\
\hline \multirow{2}{*}{$\begin{array}{l}\text { Services to organize } \\
\text { accounting }\end{array}$} & Importance & 101 & 15 & 14 & 26 & 26 & 20 & 3,22 & 1,32 \\
\hline & \begin{tabular}{|l|}
$\begin{array}{l}\text { Current } \\
\text { state }\end{array}$ \\
\end{tabular} & 46 & 5 & 4 & 18 & 16 & 3 & 3,17 & 1,06 \\
\hline \multirow{2}{*}{$\begin{array}{l}\text { Services upon ow nership and } \\
\text { generational changes }\end{array}$} & Importance & 99 & 14 & 15 & 30 & 17 & 23 & 3,20 & 1,34 \\
\hline & \begin{tabular}{|l|}
$\begin{array}{l}\text { Current } \\
\text { state }\end{array}$ \\
\end{tabular} & 40 & 4 & 3 & 25 & 4 & 4 & 3,03 & 1,00 \\
\hline \multirow[b]{2}{*}{ Marketing services } & Importance & 102 & 12 & 14 & 33 & 30 & 13 & 3,18 & 1,18 \\
\hline & \begin{tabular}{|l|}
$\begin{array}{l}\text { Current } \\
\text { state }\end{array}$ \\
\end{tabular} & 45 & 6 & 10 & 16 & 7 & 6 & 2,93 & 1,21 \\
\hline \multirow[b]{2}{*}{ Export and import services } & Importance & 101 & 17 & 17 & 31 & 17 & 19 & 3,04 & 1,33 \\
\hline & \begin{tabular}{|l}
$\begin{array}{l}\text { Current } \\
\text { state }\end{array}$ \\
\end{tabular} & 45 & 3 & 11 & 12 & 15 & 4 & 3,13 & 1,10 \\
\hline \multirow{2}{*}{$\begin{array}{l}\text { Incubation and grow th } \\
\text { services }\end{array}$} & Importance & 98 & 17 & 22 & 24 & 23 & 12 & 2,91 & 1,29 \\
\hline & $\begin{array}{l}\text { Current } \\
\text { state }\end{array}$ & 39 & 3 & 6 & 16 & 9 & 5 & 3,18 & 1,10 \\
\hline \multirow[b]{2}{*}{ Innovation services } & Importance & 98 & 15 & 23 & 27 & 22 & 11 & 2,91 & 1,24 \\
\hline & \begin{tabular}{|l|}
$\begin{array}{l}\text { Current } \\
\text { state }\end{array}$ \\
\end{tabular} & 42 & 4 & 9 & 20 & 7 & 2 & 2,86 & 0,98 \\
\hline \multirow{2}{*}{$\begin{array}{l}\text { Business location and } \\
\text { premises }\end{array}$} & Importance & 100 & 17 & 22 & 30 & 16 & 15 & 2,90 & 1,29 \\
\hline & \begin{tabular}{|l}
$\begin{array}{l}\text { Current } \\
\text { state }\end{array}$ \\
\end{tabular} & 41 & 5 & 5 & 16 & 12 & 3 & 3,07 & 1,10 \\
\hline \multirow{2}{*}{$\begin{array}{l}\text { Studios as development } \\
\text { environments }\end{array}$} & Importance & 92 & 24 & 20 & 22 & 17 & 9 & 2,64 & 1,31 \\
\hline & \begin{tabular}{|l} 
Current \\
state
\end{tabular} & 36 & 4 & 11 & 10 & 7 & 4 & 2,89 & 1,19 \\
\hline
\end{tabular}

